\title{
Corrected Age
}

National Cancer Institute

\section{Source}

National Cancer Institute. Corrected Age. NCI Thesaurus. Code C114089.

Chronological age reduced by the number of weeks born before 40 weeks of gestation;

most appropriately used to describe children up to 3 years of age who were born

preterm. 